Original article

\title{
Spirituality health and its related factors in students of nursing and midwifery
}

\author{
Samaneh Emami ${ }^{1}$, Masoumeh Bagheri-Nesami ${ }^{2 *}$, Sina Sabourian-Jouybari ${ }^{1}$, Seyede Zeynab Mazloumi-Baghloui ${ }^{1}$
}

(Received: 19 Jul 2016; Accepted: 18 Nov 2016)

\begin{abstract}
Background and Purpose: Spiritual well-being plays an important role in the mental and physical health, and is considered as a common strategy to cope with problems. Given the importance of promoting spiritual well-being in the nursing and midwifery students, we must first determine the level of this state in this population. Regarding this, the present study aimed to examine the spiritual wellbeing and its related factors in the nursing and midwifery students of Mazandaran University of Medical Sciences, Sari, Iran.

Methods: This descriptive analytical study was conducted on 183 nursing and midwifery students studying at the Mazandaran University of Medical Sciences in 2015. The sampling was performed using the systematic random sampling technique. The research instruments included a demographic form and the Spiritual Well-Being Scale developed by Palotzian and Ellison. The data were analyzed through the SPSS version 16 using the descriptive and analytical tests, including frequency, percentage, t-test, and Pearson correlation coefficient. Results: According to the results of the present study, the mean spiritual well-being was $69.70 \pm 11.62$. In addition, the means of religious and existential well-being were $35.77 \pm 6.80$ and $34.04 \pm 6.19$, respectively. The results demonstrated no significant correlation between the demographic variables and spiritual well-being in the participants $(P>0.05)$. However, spiritual well-being had a significant relationship with the religious and existential well-being $(P<0.001)$.

Conclusion: As the findings of the present study indicated, the majority of the nursing and midwifery students had a moderate level of spiritual well-being. Furthermore, religious well-being was found to be slightly higher than the existential well-being, which could be due to the cultural issues.
\end{abstract}

Keywords: Nursing, Midwifery, Spiritual well-being, Students, University of medical sciences

\section{Introduction}

Spiritual well-being is the newest dimension of health that is located next to other health aspects (1). Understanding this dimension of human existence is very important for the nurses, since nursing is a holistic major that focuses on all aspects of human existence (2). Holistic care is one of the known terms for each nurse in the last decade on which most of the nursing models and patterns has been built. Spiritual care is considered as an integral part and core of holistic care (3). However, there are various studies indicating that in practice, over $\% 50$ of the nurses do not pay attention to the patient's spiritual care and feel they have not achieved the necessary skills and abilities in this regard (4).

Today, the medical science confirms the close relationship of the physical health with mental health (5). Spirituality, as an important aspect of human existence, has a significant relationship

\footnotetext{
${ }^{1}$ Student Research Committee, School of Nursing and Midwifery, Mazandaran University of Medical Sciences, Sari, Iran

2,* Corresponding author: Department of Medical and Surgical Nursing, Infection Diseases Research Center with Focus on Nosocomial Infection, Mazandaran University of Medical Sciences, Sari, Iran. Email: anna3043@gmail.com
} 
with people's health (6). Spiritual well-being can be considered as one of the important health dimensions. This state facilitates the provision of a coordinated and integrated relationship between the internal forces. Spiritual well-being is associated with such features as consistency in life, peace, coordination and harmony, as well as feeling of having a close relationship with self, God, society, and environment (7).

In general, spirituality has a key role in the mental and physical health of an individual and is considered as a common strategy to deal with different problems (8). In case the spiritual wellbeing is seriously compromised, an individual may get such mental disorders as loneliness, depression, and loss of meaning in life (9). Inattention to each of the aspects of the human existence removes an important part of it (10).

According to the literature, the nurses need to receive adequate training on spiritual care in order to be enable to appropriately understand and promote the patient's spiritual needs (11). Regarding the importance of promoting spiritual well-being in the nursing and midwifery students, we must first determine the level of this state in this population (12). Since the nursing students are potential people for giving nursing care in the future, paying attention to their spiritual well-being is an important issue. Nevertheless, limited number of studies have investigated this issue.

In a study conducted on the nursing and midwifery students of Kerman university of Medical Sciences, Kerman, Iran, the scores of the spiritual well-being was reported to be at a moderate level (13). Based on the available databases, there are a few studies investigating the spiritual well-being and its related factors among the students. With this background in mind, the present study aimed to examine the spiritual well-being and its related factors among the nursing and midwifery students of Nasibeh School of Nursing and Midwifery, Sari, Iran, in 2015.

\section{Materials and Methods}

This descriptive analytical study was conducted on the nursing and midwifery students studying at the Nasibeh School of Nursing and Midwifery in 2015. The sample size was estimated to be 217 cases using the Morgan table; however, 183 students were willing to participate in this study. The sampling was performed using the systematic random sampling technique. The data were collected through a demographic form and the Spiritual Well-Being Scale developed by Pallotzian and Elisson (14).

The demographic form included such data as age, gender, marital status, education, occupation, income, opioid dependence, hookah smoking, number of family members, and field of study. The Spiritual Well-Being Scale consists of 20 items. This scale is divided into two subscales, namely religious well-being and existential well-being, each of which includes 10 items with a score range of 10-60. The items with odd numbers measure the religious well-being, and those with even numbers evaluate the existential well-being.

The score of spiritual well-being is calculated by summing up the score of these two subscales, which ranges within 20-120. This instrument is rated on a 6-point Likert scale ranging from strongly disagree to strongly agree. The items of this scale are reversely scored. In other words, in items 3, 4, $7,8,10,11,14,15,17,19$, and 20 , fully disagree was given score 1 , and in items 1, 2, 5, 6, 9, 12, 13, 16 , and 18 , fully disagree got the score 6 .

The score ranges of 20-40, 41-99, and 100-120 are indicative of low, medium, and high levels of spiritual well-being, respectively. The reliability of this scale was reported to be 0.82 . This scale was implemented on 283 nursing students of Shahid Beheshti University in Tehran, Iran, which showed a reliability coefficient of 0.82 (15). The data were analyzed by the SPSS version 16 using descriptive statistics (i.e., mean, standard deviation, frequency, and percentage) and inferential statistics such as independent t-test and Pearson correlation coefficient.

\section{Results}

According to the results, the mean age of the students was $22.12 \pm 2.24$ years. Out of the 183 participants, 95 (51.9\%) and $85(48.1 \%)$ cases were 
Table 1. Frequency of the participants' demographic variables

\begin{tabular}{|c|c|c|c|}
\hline \multirow[t]{2}{*}{ Variables } & & \multicolumn{2}{|c|}{ Frequency } \\
\hline & & Absolute & Relative \\
\hline \multirow{2}{*}{ Gender } & Female & 103 & 56.3 \\
\hline & Male & 80 & 43.7 \\
\hline \multirow{4}{*}{ Marital status } & Single & 145 & 79.2 \\
\hline & Married & 35 & 19.1 \\
\hline & Divorced & 2 & 1.1 \\
\hline & Widow/widower & 1 & 0.5 \\
\hline \multirow{2}{*}{ Place of residence } & City & 146 & 79.7 \\
\hline & Village & 37 & 20.3 \\
\hline \multirow{2}{*}{ Field of study } & Nursing & 95 & 51.9 \\
\hline & Midwifery & 85 & 48.1 \\
\hline \multirow{4}{*}{ Economic status } & Excellent & 12 & 6.6 \\
\hline & Good & 95 & 51.9 \\
\hline & Average & 65 & 35.5 \\
\hline & Weak & 11 & 6 \\
\hline \multirow{2}{*}{ Home status } & Own & 158 & 86.4 \\
\hline & Rental & 25 & 18.6 \\
\hline \multirow{7}{*}{ Academic semester } & 2 & 15 & 8.2 \\
\hline & 3 & 34 & 18.6 \\
\hline & 4 & 20 & 10.9 \\
\hline & 5 & 45 & 24.6 \\
\hline & 6 & 25 & 13.7 \\
\hline & 7 & 30 & 16.4 \\
\hline & 8 & 14 & 7.7 \\
\hline \multirow{2}{*}{ Opioid dependence } & Yes & 15 & 8.2 \\
\hline & No & 168 & 91.8 \\
\hline \multirow{2}{*}{ Hookah smoking } & Yes & 34 & 18.6 \\
\hline & No & 149 & 81.4 \\
\hline \multirow{5}{*}{ Number of children } & 0 & 16 & 91.3 \\
\hline & 1 & 9 & 4.9 \\
\hline & 2 & 2 & 1.1 \\
\hline & 3 & 2 & 1.1 \\
\hline & 4 & 3 & 1.6 \\
\hline
\end{tabular}

studying nursery and midwifery, respectively. The majority of the students were female $(56.3 \%)$ and single (79.2\%); in addition, most of them (91.3\%) had no child. Additionally, 95 (51.9\%) students reported to have good economic status. Most of the participants were not opioid dependent (91.8\%) and did not use hookah (81.4\%) (Table 1).

The means of the students' religious and existential well-being were $35.77 \pm 6.80$ and $34.04 \pm 6.19$, respectively. In addition, the total mean score of spiritual well-being was $69.70 \pm 11.62$, which was indicative of a moderate level. Out of the 183 nursing and midwifery students, 9 (4.6\%), 170 (93.3\%), and 4 (2.1\%) subjects had low (20-40), moderate (41-99), and high (100-120) levels of spiritual well-being, respectively.

There was no significant correlation between the demographic variables and spiritual well-being in the participants $(P>0.05)$. Nonetheless, spiritual wellbeing had a significant relationship with the religious and existential well-being $(P<0.05)$ (Table 2).

\section{Discussion}

As the results indicated, the total mean score of spiritual well-being was $69.70 \pm 11.62$. In a study conducted by Rahimi et al., the mean score of spiritual well-being in the nursing and midwifery students of Kerman University of Medical Sciences, Kerman, Iran, was reported to be $93.01 \pm 13.87$. Similar to the present study, these students had a moderate level of spiritual well-being (13). Likewise, Moghimian et al. revealed that students' spiritual level was average (16). In the mentioned study, most of the students had a medium level of spiritual well-being, and only a few of them enjoyed a high level of this state.

Additionally, in a study conducted on the students of Qom University of Medical Sciences, Qom, Iran,

Table 2. Correlation coefficient between demographic variables and spiritual well-being

\begin{tabular}{|c|c|c|c|c|c|c|c|c|c|c|c|c|c|c|}
\hline Variable & Age & Gender & $\begin{array}{c}\text { Marital } \\
\text { status }\end{array}$ & $\begin{array}{l}\text { Place of } \\
\text { residence }\end{array}$ & $\begin{array}{l}\text { Number } \\
\text { of } \\
\text { children }\end{array}$ & $\begin{array}{l}\text { Number } \\
\text { of family } \\
\text { members }\end{array}$ & $\begin{array}{c}\text { Field of } \\
\text { study }\end{array}$ & $\begin{array}{l}\text { Academic } \\
\text { semester }\end{array}$ & $\begin{array}{c}\text { Economic } \\
\text { status }\end{array}$ & $\begin{array}{l}\text { Home } \\
\text { status }\end{array}$ & $\begin{array}{c}\text { Opioid } \\
\text { dependence }\end{array}$ & $\begin{array}{l}\text { Hookah } \\
\text { smoking }\end{array}$ & $\begin{array}{l}\text { Religious } \\
\text { well-being }\end{array}$ & $\begin{array}{l}\text { Existential } \\
\text { well-being }\end{array}$ \\
\hline $\begin{array}{l}\text { Spiritual } \\
\text { well- } \\
\text { being }\end{array}$ & $\begin{array}{l}\mathrm{r}=0.011 \\
P=0.887\end{array}$ & $\begin{array}{l}\mathrm{r}=0.089 \\
P=0.231\end{array}$ & $\begin{aligned} \mathrm{r} & =0.36 \\
P & =0.626\end{aligned}$ & $\begin{array}{c}\mathrm{r}=0.082 \\
P=0.269\end{array}$ & $\begin{array}{l}\mathrm{r}=0.020 \\
P=0.733\end{array}$ & $\begin{array}{l}\mathrm{r}=0.079 \\
P=0.287\end{array}$ & $\begin{array}{l}\mathrm{r}=0.119 \\
P=0.108\end{array}$ & $\begin{array}{l}\mathrm{r}=0.078 \\
P=0.294\end{array}$ & $\begin{array}{l}\mathrm{r}=0.065 \\
P=0.384\end{array}$ & $\begin{array}{l}\mathrm{r}=-0.039 \\
P=0.686\end{array}$ & $\begin{array}{l}\mathrm{r}=0.043 \\
P=0.561\end{array}$ & $\begin{array}{l}\mathrm{r}=0.023 \\
P=0.763\end{array}$ & $\begin{array}{l}\mathrm{r}=0.809 \\
P=0.000\end{array}$ & $\begin{array}{l}\mathrm{r}=0.813 \\
P=0.000\end{array}$ \\
\hline
\end{tabular}


the students' spiritual well-being was reported to be at a desirable level, which is inconsistent with the results of the present study (17). This could be due to the fact that Qom is a holy city. However, the students' spiritual well-being can be expanded by education (18). In the previous studies, no significant relationship between the spiritual well-being and demographic variables were reported $(19,20)$.

It is indicated in a study that It is indicated in a study that attraction to spiritual and it's experience could be efficient in persons adaption; however, it depends on the age and gender of the people (21). In a study, the spiritual well-being and age were reported to have a significant relationship $(P<0.04)$ (19). Similarly, the effect of age on spiritual wellbeing has been suggested in other studies $(22,23)$. This discrepancy between or results and those of the aforementioned studies can be ascribed to the family culture and living environment of the students, who constituted the research population. In addition, this may be due to the students' lack of attention and spending time when filling out the questionnaires.

It is stated that aging improves the individuals' attraction toward spirituality since by aging, people are more involved with the fact of death and harmonize with it (24). Another reason is that an individual's worldview is getting changed from materialistic and logical to more cosmic and transcendental as he/she grows older (25). In a study, the mean spiritual well-being was reported to be a little higher in the males than that in the females. Nevertheless, no significant relationship was indicated between spiritual well-being and gender (26).

According to the results of the present study, there was no significant relationship between the age and spiritual well-being. This finding can be due to the dispersion of the student's age. Similarly, in a study, the relationship between various age groups and spiritual well-being was not significant. However, the highest spiritual well-being score was observed in the age group of 22-24 (17). In the present study, the student's academic semester was not associated with their spiritual well-being. Nonetheless, in a study, the spirituality of the senior university students was revealed to be higher than that of the junior students (27). Therefore, more studies are needed to be conducted in this regard.

In order to improve the spirituality in the students, the university authorities should develop an accurate plan. The spiritual well-being has important effects on the educational performance and other life aspects of the nursing and midwifery students. Training is an essential measure in the achievement of higher levels of spiritual well-being.

As the findings of the present study indicated, the majority of the nursing and midwifery students possessed a moderate level of spiritual wellbeing. Furthermore, no significant relationship was observed between the demographic variables and spiritual well-being. Since this study targeted the nursing and midwifery students as the study population, our results cannot be generalized to the students majoring in other fields or other people. Regarding this, further studies are recommended to investigate spiritual well-being in a larger sample of students majoring in various fields.

\section{Conclusion}

As the findings of the present study indicated,the majority of the nursing and midwifery students had a moderate level of spiritual well-being. religious well-being was found to be slightly higher than the existential well-being, which could be due to the cultural issues.

\section{Conflicts of interest}

None declared.

\section{Authors' contributions}

considering that the spiritual well-being in nursing and midwifery students is not enough, the writers aimed to provide background for training logical and thinker students.

\section{Acknowledgements}

Hereby, we express our gratitude to the Research 
and Technology Deputy of Mazandaran University of Medical Sciences, the officials of Nasibeh Nursing and Midwifery School, and all the students participating in this study. This article was approved by the Research Committee of Mazandaran University of Medical Sciences (research project number: 263-94).

\section{References}

1. Assarroudi A, Jalilvand MR, Oudi D, Akaberi A. The relationship between spiritual well-being and life satisfaction in the nursing staff of Mashhad Hasheminezhad Hospital (2011). Mod Care J 2012; 9(2):156-62 (Persian).

2. Sabzevari S, Jafari M, Borhani F, Baneshi M. View of nursing students and nurses to the pastoral care of Kerman University of Medical Sciences. Figh Med J 2012; 5(1516):119-33 (Persian).

3. McSherry W. The principal components model: a model for advancing spirituality and spiritual care within nursing and health care practice. J Clin Nurs 2006; 15(7):905-17.

4. So WS, Shin HS. From burden to spiritual growth: Korean students' experience in a spiritual care practicum. J Christ Nurs 2011; 28(4):228-34.

5. Salehi L, Soleymanizadeh L, Bagheri YS, Abbaszadeh A. The relationship between religious beliefs and locus of control with mental health. J Qazvin Univ Med Sci 2007; 11(1):50-5 (Persian).

6. Faribors B, Fatemeh A, Hamidreza H. The relationship between nurses' spiritual intelligence and happiness in Iran. Proc Soc Behav Sci 2010; 5:1556-61.

7. Craven RF, Hirnle CJ, Jensen S. Fundamentals of nursing: Human health and function. Philadelphia: Lippincott Williams \& Wilkins; 1992.

8. Mahbobi M, Etemadi M, Khorasani E, Ghiasi M. The relationship between spiritual well-being and social anxiety in chemical veterans. J Mil Med 2012; 14(3):186-91.

9. Seyed FN, Rezaei M, Givari A, Hosseini F. Prayer and spiritual well-being in cancer patients. Payesh 2006; 5(4):295-303 (Persian).

10. Khalili F, Izanloo T, Asayesh H, Abdollah Tabar H. The association between praying related attitude and behaviors and students' mental health. J Gorgan Facul Nurs Midwifery 2012; 7(1):55-62 (Persian).

11. Lantz CM. Teaching spiritual care in a public institution: legal implications, standards of practice, and ethical obligations. J Nurs Educ 2007; 46(1):33-8.

12. Farahaninia M, Abbasi M, Givari A, Haghani H. Nursing students' spiritual well-being and their perspectives towards spirituality and spiritual care perspectives. Iran J Nurs 2006; 18(44):7-14 (Persian).

13. Rahimi N, Nouhi E, Nakhaee N. Spiritual well-being among nursing and midwifery students at Kerman university of medical sciences. J Hayat 2014; 19(4):74-81 (Persian).

14. Seyed FN, Rezaei M, Givari A, Hosseini F. Prayer and spiritual well-being in cancer patients. Payesh 2006; 5(4):295-303 (Persian).

15. Alizadeh N, Bagheri Mosannan SH, Darjani A, Abdi H. Medical students viewpoints about the quality of education in department of dermatology, Guilan university of medical sciences. Res Med Educ 2014; 6(1):72-7 (Persian).

16. Moghimian M, Salmani F, Azarbarzin M. The relationship between test anxiety and spiritual well-being in nursing students. J Qom Un Med Sci J 2011; 1(5):31-6 (Persian).

17. Tabibi M, Arabshahi SK, Abdi Z, Safaeipour R. The association between spiritual well-being and academic achievement in medical students of Qom university of medical sciences, 2011. Qom Univ Med Sci J 2013; 7(1):72-8 (Persian).

18. Tavan H, Taghinejad H, Sayehmiri K, Yary Y, Fathizadeh $\mathrm{H}$, Saraby A, et al. Spiritual well-being of nursing students. Islam Health 2015; 2(1):26-32 (Persian).

19. Zare A, Jahandideh $\mathrm{S}$. The impact of special wards nursing spiritual well-being upon patients'spiritual care. Iran J Nurs Res 2014; 9(3):30-8.

20. Jadidi A, Farahaninia M, Janmohammadi S, Haghani H. Spiritual well being of elderly people resident in nursing home. J Geriatric Nurs 2015; 1(2):22-30 (Persian).

21. Karren KJ, Smith L, Gordon KJ. Mind/body health: the effects of attitudes, emotions, and relationships. New York: Pearson Higher Ed; 2013.

22. Cavendish R, Konecny L, Mitzeliotis C, Russo D. Spiritual care activities of nurses using nursing interventions classification (NIC) labels. Int J Nurs Know 2003; 14(4):113-24.

23. McSherry W. Making sense of spirituality in nursing practice: an interactive approach. Philadelphia: WB Saunders Company; 2000.

24. Chuengsatiansup K. Spirituality and health: an initial proposal to incorporate spiritual well-being in health impact assessment. Environ Impact Assess Rev 2003; 23(1):3-15. 
25. Heydari-Fard J, Bagheri-Nesami M, Mohammad-pour RA. Association between quality of life and spiritual well-being in community dwelling elderly. Life Sci J 2012; 9(4):3198-204.

26. Janbabaei G, Esmaeili R, Mosavinasab N, Rajbar M. A survey of the role of spiritual well-being and its related factors in the patients with metastatic digestive cancer. J Relig Health 2014; 2(1):9-14 (Persian).

27. Lippman LH, McIntosh H. The demographics of spirituality and religiosity among youth: international and US Patterns. Child Trends Res Brief 2010; 2010:21. 